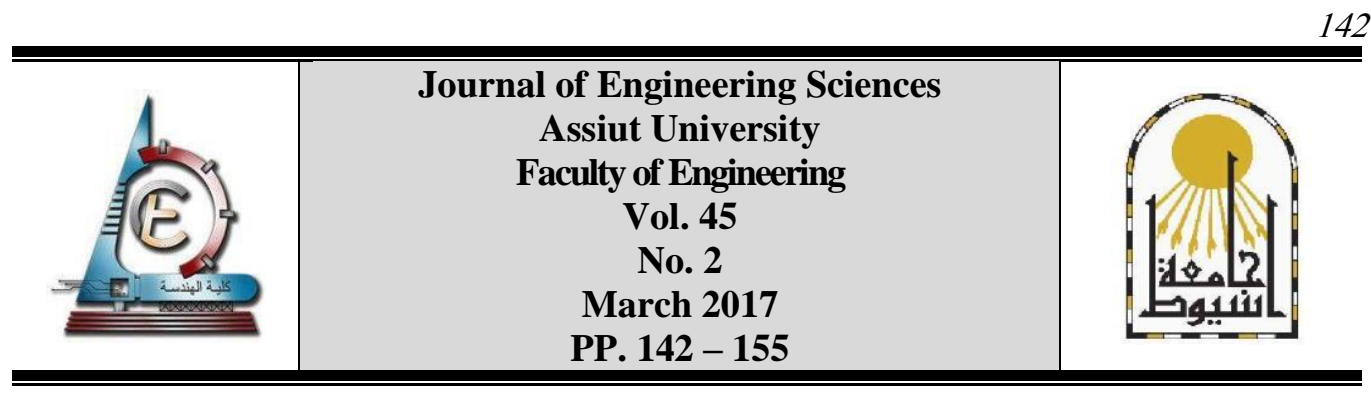

\title{
EFFECT OF NITROGEN GAS RATIO ON THE PROPERTIES OF TI-ZR-N COATINGS DEPOSITED BY PULSED MAGNETRON SPUTTERING
}

\author{
F. M. El-Hossary ${ }^{1}$, A. M. Abd El-Rahman ${ }^{2}$, Moataz H. Ata ${ }^{3}$, and M.A.Hassan ${ }^{4}$ \\ ${ }^{1,2}$ Physics Department, Faculty of Science, Sohag University, Sohag, Egypt \\ ${ }^{3,4}$ Mechanical Department, Faculty of Industrial Education, Sohag University, Sohag, Egypt
}

Received 29 January 2017; Accepted 28 February 2017

\begin{abstract}
The aim of this paper was to study the effectiveness of $\mathrm{N}_{2} / \mathrm{Ar}$ gas ratio on the mechanical and tribological properties of Ti-Zr-N films coated on (AISI 304 stainless steel) substrate. The thin films were produced at $150 \mathrm{~W}$ pulsed magnetron sputtering (PMS) technique operated for $90 \mathrm{~min}$. The structure and tribo-mechanical properties of the Ti-Zr-N coatings were investigated at different $\mathrm{N}_{2} / \mathrm{Ar}$ gas pressure ratio. X-ray diffraction (XRD), microhardness, surface roughness, wear and friction, corrosion performance and surface energy were investigated. The analysis of X-ray diffraction (XRD) indicated a formation of solid solution phase of $(\mathrm{Ti}-\mathrm{Zr}) \mathrm{N}$ with (FCC) structure and a chemical compound phase of TiN. The solid solution phase (Ti-Zr)N has the orientation (111). The microhardness of the thin films has high values compared to associated value of (AISI 304 stainless steel) substrate; up to 4-folds. Furthermore, the wear performance was improved from $73.06 \mathrm{~mm}^{3} / \mathrm{m}$ for AISI substrate to $5.01 \mathrm{~mm}^{3} / \mathrm{m}$ after depositing Ti-Zr-N. The coefficient of friction was decreased from nearly 0.69 for the austenitic substrate to nearly 0.12 after coating with Ti-Zr-N. Over and above, the corrosion resistance substantially improved (factor of 1000 times) after the coating.
\end{abstract}

\section{Introduction}

Hard protective films were hired to protect different metallic tools and components for various industrial applications [1,2]. Nitride transition metal coatings are employed for reinforcing the tribological and mechanical performance and the service quality of heavy use in industrial machinery tools and automobile parts $[3,4]$. Binary nitride coatings such as TiN, $\mathrm{ZrN}$ and $\mathrm{CrN}$ are now commercially used for such purposes [5-7]. However, the low oxidation temperature of binary nitride coatings obstructs some of their applications, particularly in dry and high-speed machining operations. TiN and $\mathrm{ZrN}$ coatings are isothermally oxidized at temperature around $400^{\circ} \mathrm{C}[8,9]$. Instead, hard protective ternary nitride coatings were presently used in relatively sever applications in significance of an increase in their starting oxidation temperature by more than $200^{\circ} \mathrm{C}$ compared to that of TiN [10]. Among these, Ti-Zr$\mathrm{N}$ and Ti-Al-N coatings have properties as excellent tribological properties retain a low coefficient of friction (0.6-0.8) compared with TiN [11, 12] and good corrosion performance. Various physical vapor deposition (PVD) as arc deposition [13], electron beam evaporation [14], arc ion plating [15], and magnetron sputtering [16] are employed for coatings preparation. 
(PMS) has become an excellent option for the coating of metallic, low conductive and insulator materials for industrial application. This technique has some advantages comared to normal DC sputtering in which arcing is absent and deposition rate is high [17, 18]. Little previous studies $[19,20]$ reported that the nitrogen gas concentration considered as an important factor to control the mechanical properties of Ti-Zr-N coating. The purpose of this work is to investigate the effectivness of $\mathrm{N}_{2} /$ Ar gas pressure ratio on the structure, tribological and anticorrosive of Ti- $\mathrm{Zr}$ - N coatings produced by (PMS) technology.

\section{Experimental}

\subsection{Specimen preparation}

The austenitic stainless steel AISI 304 sheets were used in this study as a substrate material. The chemical composition of AISI 304 in wt $\%$ is $0.075 \mathrm{C}, 1.2 \mathrm{Mn}, 19.1 \mathrm{Cr}, 8.5 \mathrm{Ni}, 0.5 \mathrm{Si}$ and Fe balance. The AISI 304 stainless steel were machined to the size of $10 \times 20 \times 1 \mathrm{~mm}^{3}$, ground on the surface and subsequently polished mirror like with a silicon carbide paper ranging from 600 to 4000 grit on a grinder. The samples were ultrasonically cleaned in ethanol for $10 \mathrm{~min}$ before they were mounted on the substrate holder in the deposition chamber.

\subsection{Coating Preparation}

The (PMS) system consists of a stainless steel sputtering chamber of $35 \mathrm{~cm}$ diameter. The AISI substrates are set on a $50 \mathrm{~mm}$ diameter substrate holder, which is centered in front of the sputter gun in the deposition chamber. A disk form with $50 \mathrm{~mm}$ diameter and 3 mm thickness composed of $90 \% \mathrm{Ti}$ and $10 \% \mathrm{Zr}$ (purity 99.99\%) is used as a sputtering target material. The distance between the target and the substrate holder was secured at 3 $\mathrm{cm}$. After loading the substrates into the PMS chamber, the system is evacuated by two stage rotary and turbo pumps from atmospheric pressure to a base pressure of approximately $7 \times 10^{-6}$ mbar. Pure argon plasma sputtering $(150 \mathrm{~W}$ and $100 \mathrm{KHz})$ was applied on the TiZr target for 3 min to eliminate the oxide layer effect, sputter the localized states of the grown nitrides and to remove the sharp surface defects that responsible for sparking effects .The deposition of the Ti-Zr-N coatings was carried out in a mixture of Ar and $\mathrm{N}_{2}$ atmosphere under a constant power of $150 \mathrm{~W}$ for running time of $90 \mathrm{~min}$ at working pressure of $5 \times 10^{-3}$ mbar. The $\mathrm{N}_{2}$ gas ratio was varied from $10 \% \mathrm{~N}_{2}$ to $50 \% \mathrm{~N}_{2}$ with respect to the total fixed gas pressure of 7x10-6 mbar. The sample temperature was measured during the pulsed magnetron sputtering process by a chrome-alumel thermocouple, which is placed close to the surface of the sample. The measured sample temperature has a wide range from $35^{\circ} \mathrm{C}$ to $40^{\circ} \mathrm{C}$. As the deposition process is completed, the chamber is allowed to cool down before venting to atmospheric pressure.

\subsection{Surface characterization and testing}

The crystal structure of the uncoated and coated substrates was examined by X-ray diffraction (XRD) using Philips-PW1710 diffractometer with $\mathrm{Cu} \mathrm{K} \alpha$ radiation of $\lambda=$ $1.541838 \AA$. The XRD patterns were obtained with a step interval of $0.02^{\circ}$ over a wide angular range from $20^{\circ}$ to $100^{\circ}$. The surface morphology of the uncoated and coated substrates was examined by Olympus BX51 optical microscope. The microhardness measurement was evaluated using a Leitz Durimet microhardness tester equipped with the Vicker's diamond indenter; under a static load of $25 \mathrm{gmf}$. The obtained microhardness value for each sample corresponds to the mean of random 5 measures. The hardness tests were performed according to ASTM E384-11 standard test method at temperature of $25^{\circ} \mathrm{C} \pm 3^{\circ} \mathrm{C}$ 
[21]. The Vickers microhardness tester has been accredited according to the requirements of ISO/IEC 17025:2005. Wear and friction measurements were made by a ball-on disk tribometer without lubrication at room temperature in air atmosphere with humidity of $38 \%$ $\pm 5 \%$. Wear measurements were performed according to ASTMG133-10 standard test method. The friction coefficient was performed at a mean sliding speed of $10 \mathrm{~mm} / \mathrm{s}$ with a normal load of $1 \mathrm{~N}$. A $3 \mathrm{~mm}$ ball of tungsten carbide (WC) was used as counterpart material. The friction coefficient was continuously determined using a force sensor during the wear measurements. The oscillating ball-on-disk type tribometer has been accredited according to the requirements of ISO/IEC 17025:2005. The wear rates were determined according to the equation $\mathrm{K}=\mathrm{V} / \mathrm{SF}$; where $\mathrm{V}$ is the wear volume in $\mathrm{mm}^{3}, \mathrm{~S}$ is the total sliding distance in $\mathrm{mm}$ and $\mathrm{F}$ is the applied load in $\mathrm{N}$. The surface roughness of the samples was performed using a Form Talysurf 50 which has been accredited according to ISO/IEC 17025:2005 requirements. Water contact angle and surface energy were achieved using Phoenix 300, at room temperature (manufactured by S.E.O Co. Ltd). The Phoenix 300 utilized a precision camera and advanced PC technology to capture the static droplet image and determine the contact angle by Sessile Drop method. The electrochemical corrosion measurements were completed in $5 \% \mathrm{H}_{2} \mathrm{SO}_{4}+0.05 \mathrm{KSCN}$ solution using the potential dynamic technique at temperature of $25^{\circ} \mathrm{C} \pm 3^{\circ} \mathrm{C}$ and humidity of $38 \% \pm 5 \%$. The effective area of the sample exposed to corrosive solution was adjusted to be $0.36 \mathrm{~cm}^{2}$. In this study, the electrochemical test was made using three-electrodes; silver-silver chloride saturated electrode as a reference electrode, platinum as a counter electrode and the investigated sample as a working electrode. The potential-current corrosion curve of all specimens was recorded with potential scan rate of $1 \mathrm{mV} / \mathrm{s}$ using Gill AC instrument and ACM program version 5.

\section{Results and discussion}

\subsection{Microstructure analysis}

Figure 1 shows the XRD of the AISI 304 substrate without coating and that coated with $\mathrm{Ti}-\mathrm{Zr}-\mathrm{N}$ at various $\mathrm{N}_{2} / \mathrm{Ar}$ gas ratio. The microstructure of the substrate without coating is associated to austenitic stainless steel, $\gamma$-phase. After coating, the $\gamma$-austenite phase is still detected with lower intensities owing to that the coat layer thickness lies in the penetration depth of the X-rays. The XRD of the coated substrates indicate the solid solution phase of (Ti, Zr) $\mathrm{N}$ and the chemical compound phase of $\mathrm{TiN}$. The $(\mathrm{Ti}, \mathrm{Zr}$ ) $\mathrm{N}$ has a face centered cubic lattice structure. It is observed from Fig.1 that the highest intensity reflection peaks with a preferred orientation of (111) are revered to $(\mathrm{Ti}, \mathrm{Zr}) \mathrm{N}$ coated at nitrogen gas ratio of $10 \%$. However, TiN phase is also detected with much lower intensity.

The (Ti, Zr) N phase with the same preferred orientation was observed in similar coatings deposited by other PVD techniques as vacuum-arc deposition [22], DC magnetron sputtering [23], cathodic arc vapor deposition [24, 25] and unbalanced magnetron sputtering [26]. At nitrogen gas ratio of $20 \%$, the structure shows that the TiN becomes the major phase with preferred orientation (200) and weak reflections from (Ti, $\mathrm{Zr}$ ) $\mathrm{N}$ phase. Then with more increase in nitrogen gas ratio, both nitride phases are randomly detected with lower peak intensities. Grimberg et al. [27] observed weak intensities of Ti-Zr nitride phase at relatively high nitrogen pressures and this was ascribed to the genesis of a less dense Ti-Zr-N structure. The decrease in the thickness of the coating with the increase of $\mathrm{N}_{2}$ gas ratios can be considered as a further reason that affects the diffraction intensity. Otherwise, the lattice parameters of TiN and (Ti,Zr)N phases were calculated and found to be 4.24 and 4.27, 
respectively. Typical value of lattice parameter of $\mathrm{TiN}$ is previously reported [23, 28]. The increase in the lattice parameter of $(\mathrm{Ti}, \mathrm{Zr}) \mathrm{N}$ coatings compared to that of $\mathrm{TiN}$ has been previously ascribed to the substitution of $\mathrm{Ti}$ with $\mathrm{Zr}$ in the TiN lattice $\quad[19,23]$.

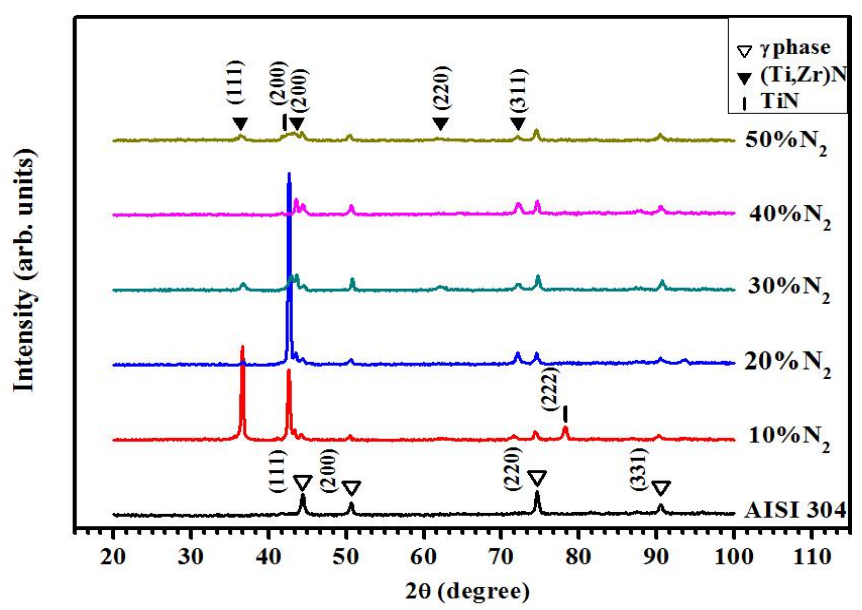

Fig. 1. XRD of AISI 304 substrate and Ti-Zr-N thin films deposited at different $\mathrm{N}_{2} \%$ gas ratios.

\subsection{Film thickness and deposition rate}

Figure 2 shows the variation of coating thickness and the deposition rate as a function of $\mathrm{N} 2 \%$ gas ratio. The coating thickness is calculated in average of five times taken along the step surface created between the coated and uncoated austenitic substrate. The deposition rate is determined using the formula of $t / s$, where $t$ is the average thickness of the thin film in $\mathrm{nm}$, and $\mathrm{s}$ is the total deposition time in sec. It is observed that the thickness and the deposition rate decrease continuously with increasing N2 ratio from $10 \%$ to $50 \%$. These results agree well with several previous works were discussed the relation between the N2 gas ratio and deposition rate [29-32]. The decreasing in deposition rate can be attributed to the reduced sputtering efficiency of reactive gas ions or a lower sputtering yield resulting from the nitrogen absorption on metal target [33].

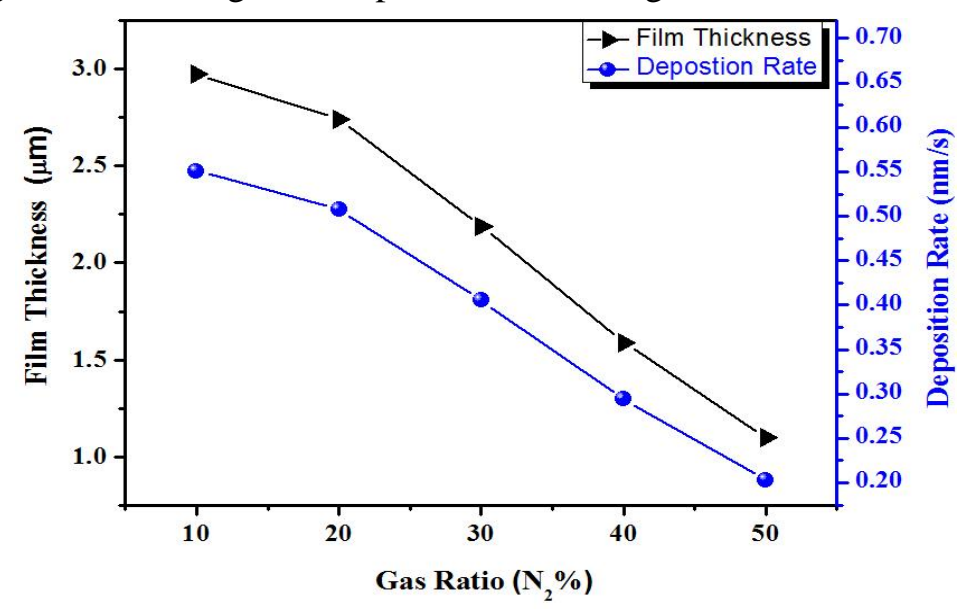

Fig. 2. Film thickness and deposition rate of Ti-Zr-N thin films as a function of $\mathrm{N}_{2} \%$ gas ratio. 


\subsection{Microhardness}

Figure 3 illustrates the microhardness values of the Ti-Zr-N thin film samples as a function of $\mathrm{N}_{2}$ gas ratio. One can see from the figure that the highest value of microhardness is recorded at $10 \% \mathrm{~N}_{2}$ and after that it significantly decreases with the increase of the $\mathrm{N}_{2}$ gas ratio. The microhardness is recorded a maximum value of an approximately $939.3 \mathrm{HV}$ at $10 \% \mathrm{~N}_{2}$ sample, which represents nearly 4 folds in comparison with the austenitic stainless steels AISI 304 substrate (234.4 HV). This improvement is mostly attributed to a solid solution strengthening mechanism which provides an energy barrier to the movement of dislocations all around the crystals that have distortion of the periodic lattice caused by the add atoms of $\mathrm{Ti}$ and $\mathrm{Zr}$ during deposition [20].

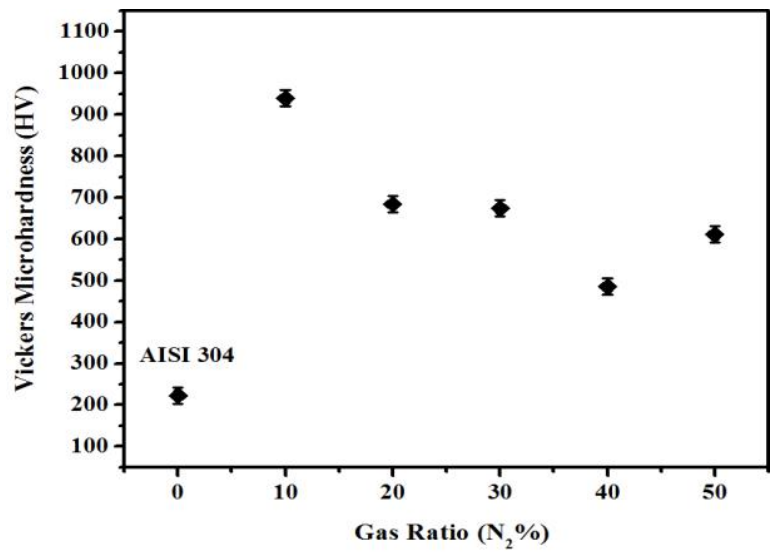

Fig. 3. Microhardness values of the Ti-Zr-N thin film as a function of $\mathrm{N}_{2} \%$ gas ratio.

The decrease in the hardness values of the samples at gas ratio higher than $10 \%$ could be due to the decrease of the solid solution (Ti,Zr)N (111) in the deposited samples. It is appeared that the behavior of microhardness is correlated with the intensity reflection peaks of metal nitride (111) which is the hardest orientation in transition metal nitride [20].

\subsection{Surface energy and surface roughness}

Figure 4 illustrates the relation between the water contact angle and surface energy of the Ti-Zr-N thin film samples as a function of $\mathrm{N}_{2}$ gas ratio. One can see from Fig. 4 that the contact angle decreases to a minimum value as the $\mathrm{N}_{2}$ gas ratio increases to $30 \% \mathrm{~N}_{2}$. On the other hand, the surface energy increases to a maximum value as the $\mathrm{N}_{2}$ gas ratio increases to $30 \% \mathrm{~N}_{2}$ due to the formation of ( $\left.\mathrm{Ti}, \mathrm{Zr}\right) \mathrm{N}$ hard phases. It has been reported where else [34] that, low contact angle and high surface energy refers to the high surface wettability and vice versa which is agree well with the present study. One can see also that the water contact angle is less than $90^{\circ}$, which could mean hydrophilic surface for all samples.

Different previous studies demonstrated a direct relationship between surface roughness, represented by Ra, and wettability of the surface [35-37]. Moreover, Feng et al. [38] reported that the greater the roughness of a surface the larger the surface energy and higher wettability. The Ra parameter is obtained from mean height of peaks and valleys on the surface. Figure 5 gives the relation between Ra of the Ti-Zr-N thin film samples as a function of $\mathrm{N}_{2}$ gas ratio. It can be seen that the surface roughness of the thin film increases up to a maximum value at $30 \%$ $\mathrm{N}_{2}$, and then after it decreases with further increase in $\mathrm{N}_{2}$ gas ratio. The increase in surface roughness is revered to ion bombardment during the deposition process [39]. 
Moataz H. Ata et al., Effect of nitrogen gas ratio on the properties of TI-ZR-N coatings deposited ...

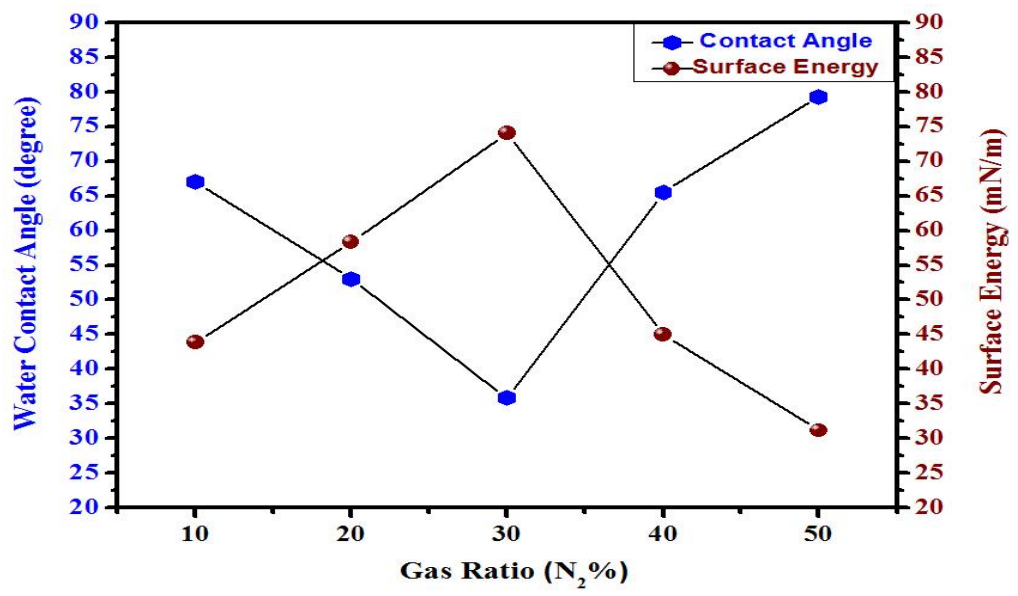

Fig. 4. Water contact angle and surface energy of the Ti-Zr-N thin films as a function of $\mathrm{N}_{2} \%$ gas ratio.

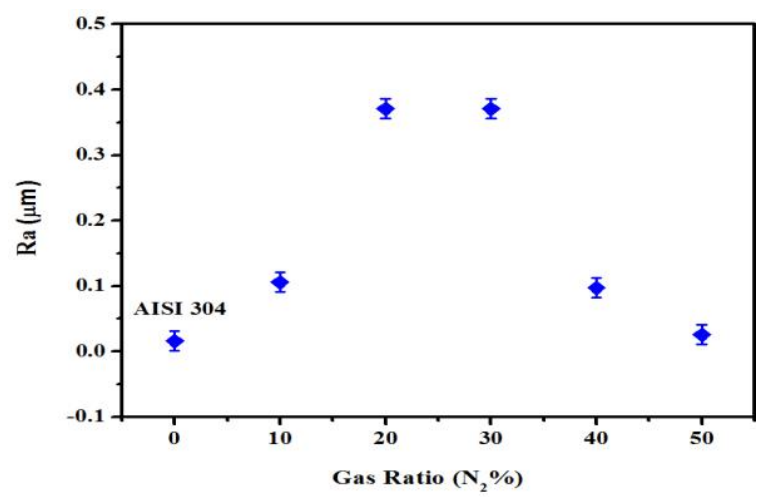

Fig. 5. Surface roughness ( $\mathrm{Ra}$ ) of the Ti-Zr-N thin films as a function of $\mathrm{N}_{2} \%$ gas ratio.

Beside the average roughness ( $\mathrm{Ra}$ ), there are other roughness parameters such as maximum profile peak heights $(\mathrm{Rp})$, maximum profile valley depths $(\mathrm{Rv})$ and $(\mathrm{Rz})$ is the sum of (Rp) and (Rv) [40]. Moreover, $R p / R z$ describes the surface roughness shape. When the surface peaks are sharp the ratio $\mathrm{Rp} / \mathrm{Rz}$ is greater than 0.5 , and when the surface has rounded peaks the ratio lower than 0.5 , which is in favor to spread out the liquids on the surface [40]. According to this assumption and the results reported in Table 1, the ratio values of $(\mathrm{Rp} / \mathrm{Rz})$ of all TiZrN surface samples are lower than 0.5 and therefore the surface exhibit rounded peaks and this lead to higher surface wettability.

Table. 1.

$\mathrm{Rp} / \mathrm{Rz}$ of Ti-Zr-N thin film deposited at different $\mathrm{N} 2 \%$ gas ratios.

\begin{tabular}{|c|c|c|c|c|}
\hline Samples & $\begin{array}{c}\mathbf{R v} \\
(\boldsymbol{\mu m})\end{array}$ & $\begin{array}{c}\mathbf{R z} \\
(\boldsymbol{\mu m})\end{array}$ & $\begin{array}{c}\mathbf{R p} \\
(\boldsymbol{\mu m})\end{array}$ & $\mathbf{R p / R z}$ \\
\hline AISI304 & 0.0972 & 0.13 & 0.0732 & 0.56 \\
\hline $\mathbf{1 0 \%} \mathbf{N}_{\mathbf{2}}$ & 1.561 & 2.0285 & 0.37752 & 0.19 \\
\hline $\mathbf{2 0 \%} \mathbf{N}_{\mathbf{2}}$ & 2.24678 & 3.1523 & 0.90556 & 0.29 \\
\hline $\mathbf{3 0 \% N _ { 2 }}$ & 2.24558 & 4.05076 & 1.8053 & 0.45 \\
\hline $\mathbf{4 0 \%} \mathbf{N}_{\mathbf{2}}$ & 1.10586 & 1.43544 & 0.32962 & 0.23 \\
\hline $\mathbf{5 0 \%} \mathbf{N}_{\mathbf{2}}$ & 0.23322 & 0.33606 & 0.10286 & 0.31 \\
\hline
\end{tabular}


JES, Assiut University, Faculty of Engineering, Vol. 45, No. 2, March 2017, pp.142-155

\subsection{Wear and friction coefficient}

The wear behavior of substrate AISI 304 and Ti-Zr-N films deposited for different $\mathrm{N}_{2}$ gas ratios was evaluated using oscillating ball-on-disk type tribometer. Figure 6 shows the optical micrograph of the wear track width of these samples. It shows that the wear track width of the $10 \% \mathrm{~N}_{2}$ sample has narrow width than that of AISI 304 sample, signifying the enhancement in the wear resistance.
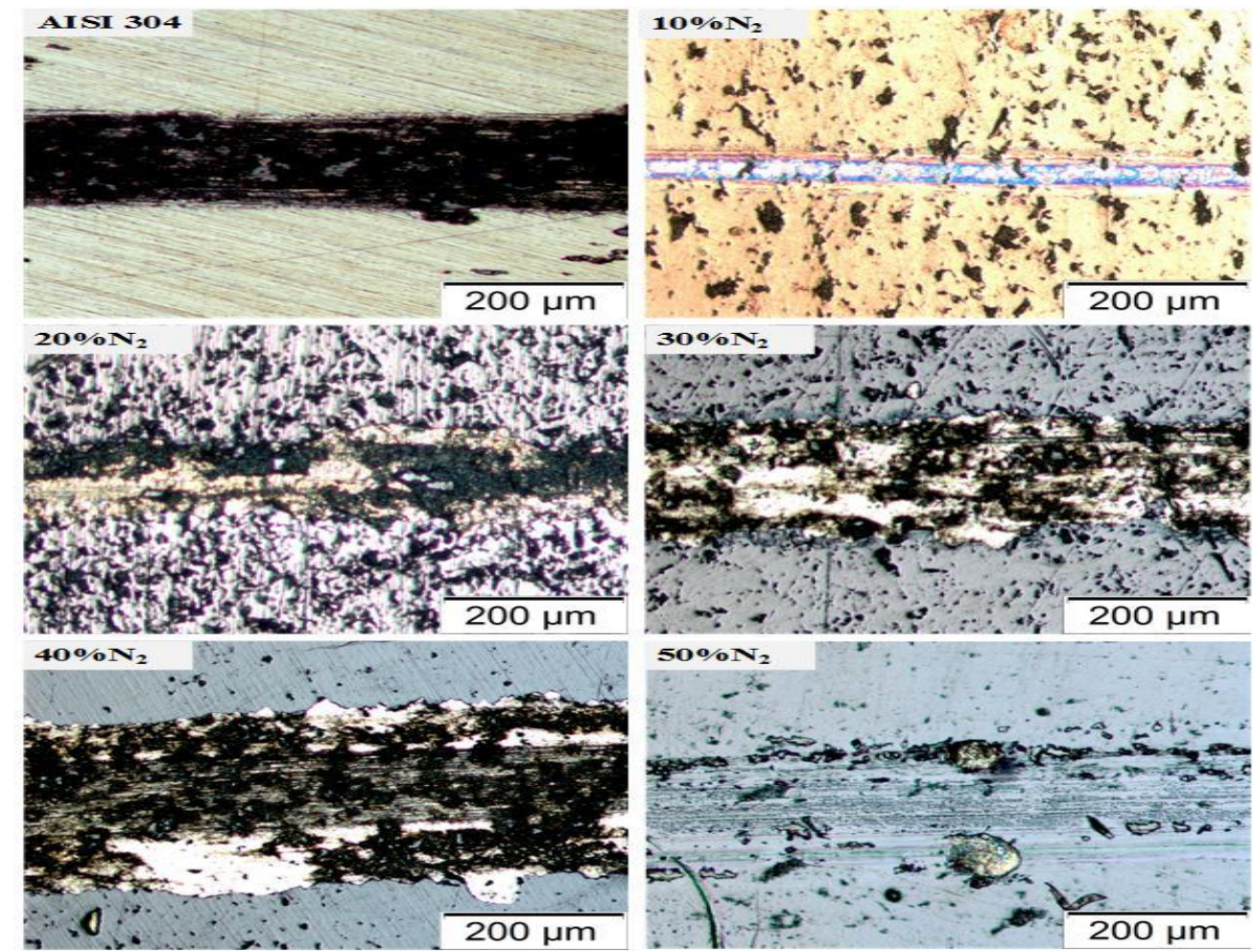

Fig. 6. Optical micrograph of wear track width of AISI 304 substrate and Ti-Zr-N thin films as a function of $\mathrm{N}_{2} \%$ gas ratio.

The improvement in the wear resistance is recognized to the surface strengthening resulting from adding $\mathrm{Zr}$ into TiN structure forming hard phase of (Ti- $\mathrm{Zr}$ ) $\mathrm{N}$ possess excellent wear resistance. Previous reporters [41, 42] stated that the titanium nitride based coatings have low friction coefficient and high wear resistance. However, the TiN coatings have a high friction coefficient and low wear resistance with respect to that of TiBN, TiAlN and TiCN [43-47]. Lugscheider et al. [48] reported that the effect of adding $\mathrm{Zr}$ into TiN structure to form Ti-Zr-N films possess excellent wear resistance due to formation of the stable oxide layers on the film and increased hardness by solid solution strengthening.

Figure 7 depicts the variations in the wear track width for the AISI 304 and Ti-Zr-N films deposited for different $\mathrm{N}_{2}$ gas ratios. The $40 \% \mathrm{~N}_{2}$ and $50 \% \mathrm{~N}_{2}$ samples have the greatest wear track width due to the absence of hard phases $(\mathrm{Ti}-\mathrm{Zr}) \mathrm{N}$ with orientation (111) and existence of TiN phase which possess low wear resistance and high friction coefficient ( 0.6 to 0.8 ) [43-45]. 


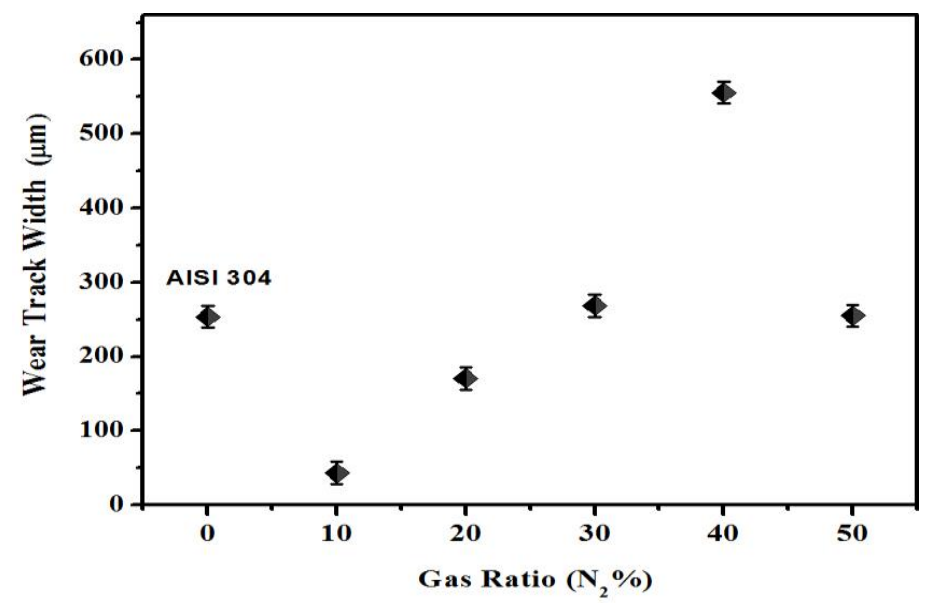

Fig.7. The wear track width of the AISI 304 substrate and Ti-Zr-N thin films of $\mathrm{N}_{2} \%$ gas ratio.

The friction coefficient of the AISI 304 substrate and Ti-Zr-N samples is shown in Figure 8. From this figure, the friction coefficient decreases approximately from 0.69 for AISI 304 substrate to 0.12 for the Ti-Zr-N sample prepared at $10 \% \mathrm{~N}_{2}$. At this condition, the Ti-Zr-N coating sample exhibit the best low friction coefficient nearly 5 times higher than the uncoated AISI 304. The change in surface chemical composition and the lower thickness of the coating for high $\mathrm{N}_{2} \%$ are reasons for the decrease in the friction coefficient.

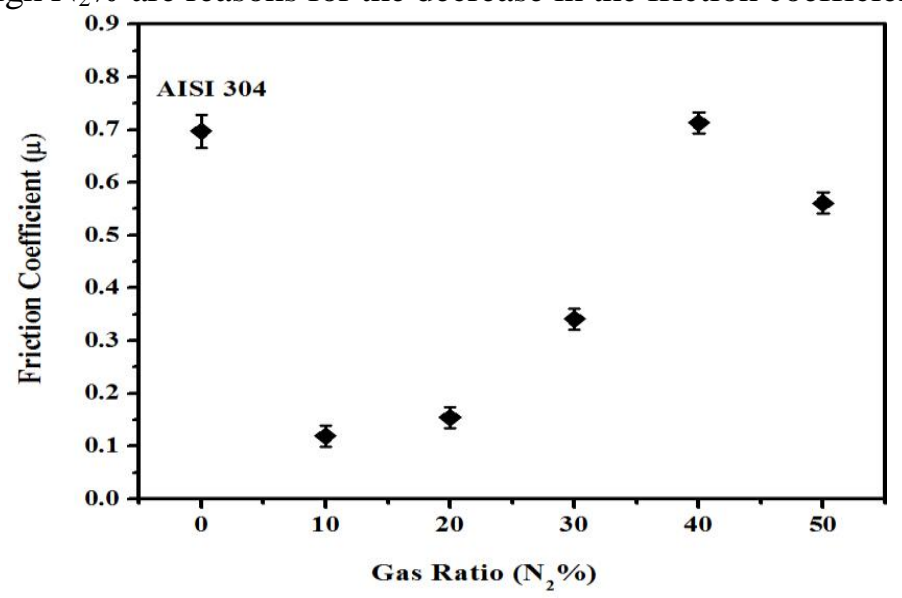

Fig. 8. The friction coefficient of AISI 304 substrate and Ti-Zr-N thin films as a function of $\mathrm{N}_{2} \%$ gas ratio.

The corresponding friction coefficients versus the sliding distance for the AISI 304 and Ti-Zr-N coating samples are shown in Figure 9. It can be found from this figure that, the $40 \% \mathrm{~N}_{2}$ and $50 \% \mathrm{~N}_{2}$ samples are the least performance of sliding rate due to the relatively small thickness of the coating and the influence abrasive wear mechanism. On the other hand, the $10 \% \mathrm{~N}_{2}$ and $20 \% \mathrm{~N}_{2}$ samples are the best performance of sliding rate which recorded no brittle failure during the wear test and it shows approximately fixed coefficient of friction at 0.12 . However, the $30 \% \mathrm{~N}_{2}$ sample shows good performance where no brittle failure during the wear test up to $12 \mathrm{~m}$ sliding distance. 


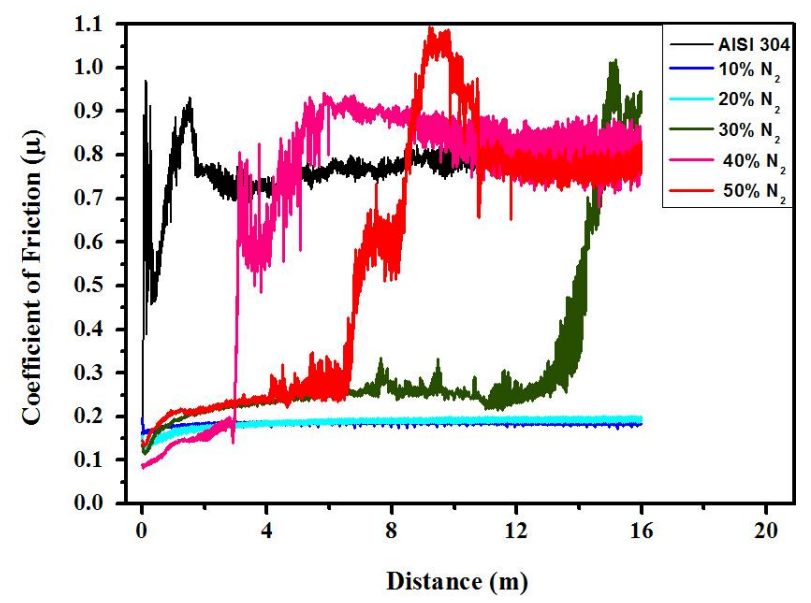

Fig. 9. Friction coefficient and sliding distance for of AISI 304 substrate and Ti-Zr-N thin films as a function of $\mathrm{N}_{2} \%$ gas ratio.

One can monitor from the figure that, the wear rate increases up to a maximum value as the $\mathrm{N}_{2}$ increases up to $40 \% \mathrm{~N}_{2}$ and then after it decreases at $50 \% \mathrm{~N}_{2}$.

Figure 10 represents the wear rate of the investigated Ti-Zr-N coatings deposited for different $\mathrm{N}_{2}$ gas ratios, where the wear rate is calculated as (the wear area $\mathrm{x}$ track length/ total sliding distance). One can monitor from the figure that, the wear rate increases up to a maximum value as the $\mathrm{N}_{2}$ increases up to $40 \% \mathrm{~N}_{2}$ and then after it decreases at $50 \% \mathrm{~N}_{2}$. From this result, it can be inferred that the $\mathrm{N}_{2}$ gas ratio is vital factor for controlling the wear resistance [49].

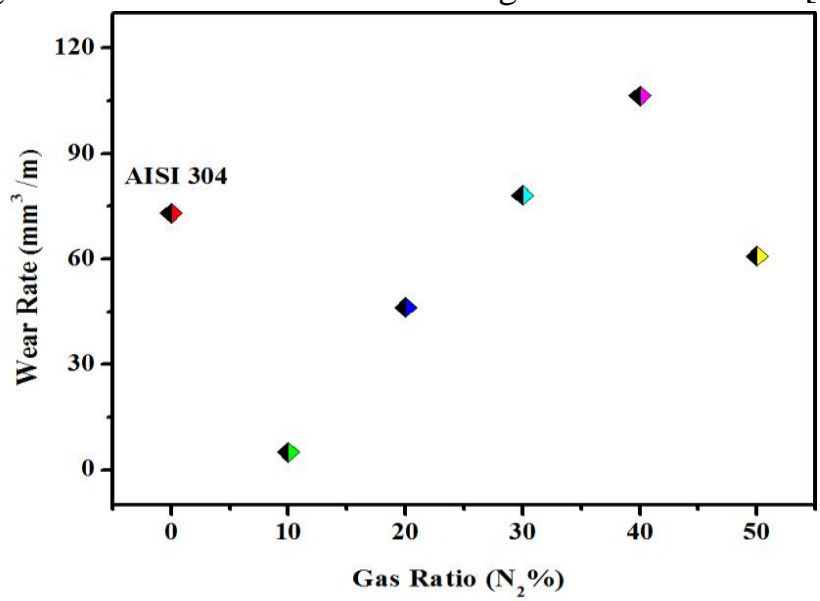

Fig. 10. The Wear rate of AISI 304 substrate and Ti-Zr-N thin films as a function of $\mathrm{N}_{2} \%$ gas ratio.

\subsection{Corrosion performance}

Figure 11 represents the results of potentiodynamic polarization scans for AISI 304 substrate and Ti-Zr-N films in a $0.5 \mathrm{M} \mathrm{H}_{2} \mathrm{SO} 4+0.05 \mathrm{M}$ KSCN solution were measured at room temperature. Moreover, the corrosion potential (Ecorr) and the corrosion current density (Icorr) which are determined from the polarization curves for all investigated samples are tabulated in table 2 . 
Moataz H. Ata et al., Effect of nitrogen gas ratio on the properties of TI-ZR-N coatings deposited ...

The results show that, the AISI 304 substrate has the highest corrosion potential and the highest corrosion current in comparison with the associated values of the Ti-Zr-N coating samples. This is in good agreement with the results reported in previous literature [50, 51]. Figure 12 illustrates the optical micrograph of the AISI 304 substrate and Ti-Zr-N coating deposited at different $\mathrm{N}_{2} \%$ gas ratios before and after immersing in corrosive media. One can detect that the changes on the surfaces after exposure to corrosive media are visible at $40 \% \mathrm{~N}_{2}$ sample which is similar to that of AISI 304 one. The changes in the other samples are indistinguishable. No pitting corrosion on the surface of the samples can be detected by optical micrograph. From the results presented in table2, Figure 11 and Figure 12 one can verify that, the corrosion resistance of AISI 304 substrate is substantially improved 1000 times when the substrate was coated with Ti-Zr-N thin film.

Table. 2.

Corrosion data for AISI 304 substrate and Ti-Zr-N films deposited at different $\mathrm{N}_{2} \%$ gas ratios.

\begin{tabular}{|c|c|c|c|}
\hline Gas Ratio $\left(\mathbf{N}_{\mathbf{2}}\right)$ & $\begin{array}{c}\mathbf{I}_{\text {corr }} \\
(\mathbf{x 1 0}\end{array}$ & $\begin{array}{c}\mathbf{E}_{\text {corr }} \\
\left.\mathbf{m A} / \mathbf{c m}^{2}\right)\end{array}$ & $\begin{array}{c}\text { Corrosion Rate } \\
(\mathbf{m V 1 0})\end{array}$ \\
\hline AISI 304 & 5331.7 & 202.06 & 5720.914 \\
\hline $\mathbf{1 0 \%} \mathbf{N}_{\mathbf{2}}$ & 3.759 & -8 & 4.03341 \\
\hline $\mathbf{2 0 \%} \mathbf{N}_{\mathbf{2}}$ & 215.16 & -270 & 241.5967 \\
\hline $\mathbf{3 0 \%} \mathbf{N}_{\mathbf{2}}$ & 2.702 & -229.14 & 2.899246 \\
\hline $\mathbf{4 0 \%} \mathbf{N}_{\mathbf{2}}$ & 719.5 & -261.67 & 772.0235 \\
\hline $\mathbf{5 0 \%} \mathbf{N}_{\mathbf{2}}$ & 50.18 & -310.24 & 53.84314 \\
\hline
\end{tabular}

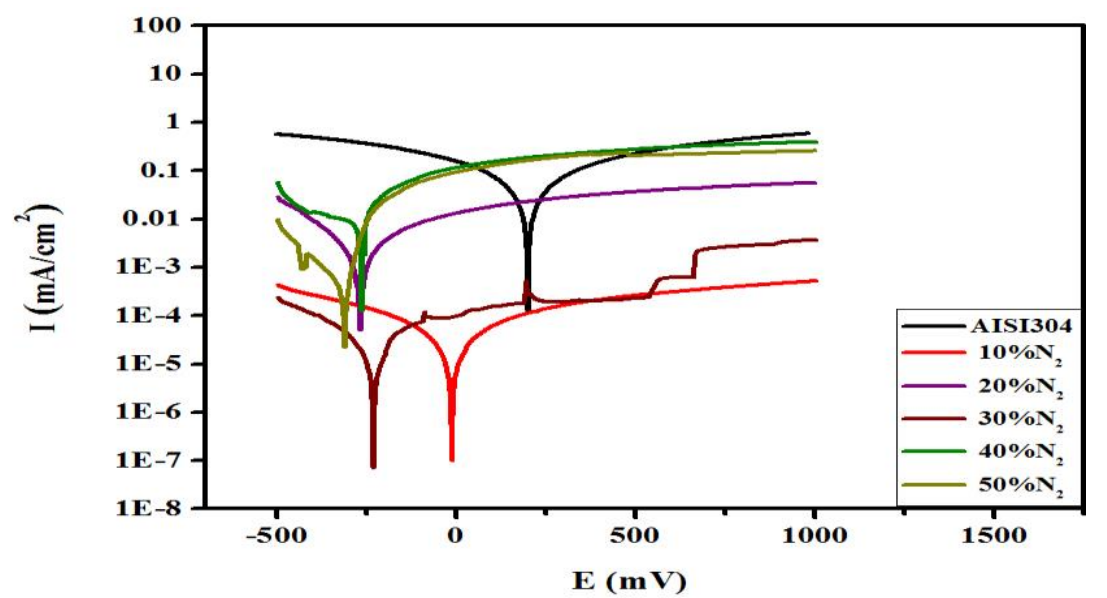

Fig. 11. The potentiodynamic polarization curves for AISI 304 substrate and Ti-Zr-N thin films as a function of $\mathrm{N}_{2} \%$ gas ratio.

\section{Conclusion}

1- A ternary Ti-Zr-N thin film was successfully deposited on AISI 304 stainless steel substrate using a pulsed magnetron sputtering technique at different $\mathrm{N}_{2} \%$ gas ratios.

2- $\mathrm{N}_{2} /$ Ar gas ratio is critical parameter for controlling the properties of deposited Ti$\mathrm{Zr}-\mathrm{N}$ thin film.

3- Low $\mathrm{N}_{2} \%$ gas ratio (10\%) produces relatively thick film contains mainly Ti-Zr-N phase with high (relative to that of AISI 304 substrate) hardness, wear resistance, corrosion resistance, high surface energy and lower friction coefficient. However, 
increasing the $\mathrm{N}_{2} \%$ gas ratio up to $50 \%$ produces less thickness films which contain mainly TiN phase with lower hardness, wear resistance and corrosion resistance. Meanwhile, the surface energy has a maximum value at $30 \mathrm{~N}_{2} \%$ gas ratio.

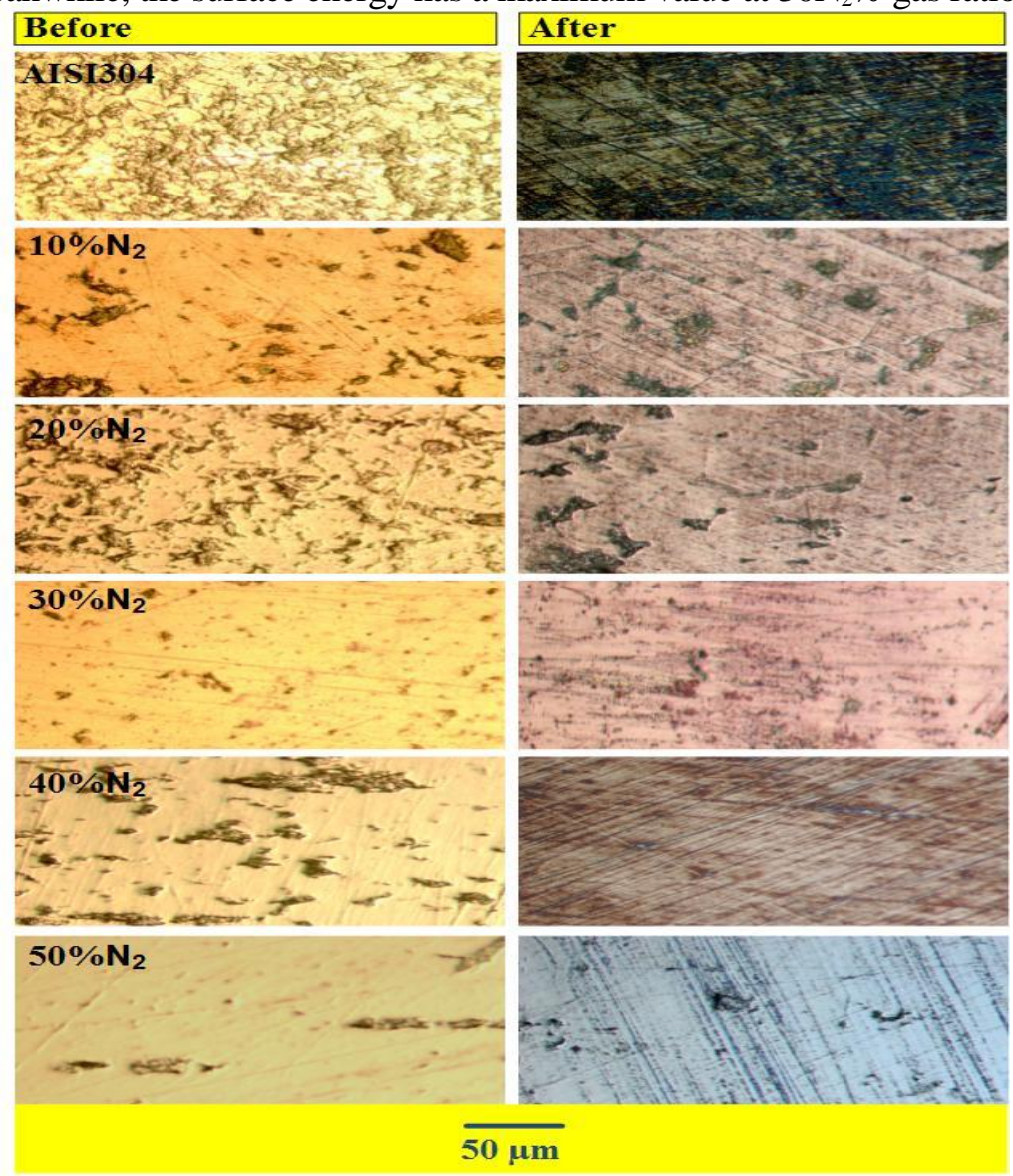

Fig. 12. Optical micrograph of AISI 304 substrate and Ti-Zr-N thin films deposited for different $\mathrm{N}_{2} \%$ gas ratios before and after immersing in a $0.5 \mathrm{M} \mathrm{H}_{2} \mathrm{SO}_{4}+0.05 \mathrm{M} \mathrm{KSCN}$ solution

\section{REFERENCES}

[1] Quinto, D. T. [1988]. "Mechanical property and structure relationships in hard coatings for cutting tools." Journal of Vacuum Science \& Technology A 6: 2149-2157.

[2] Schulz, H., et al. [2001]. "Performance of oxide PVD-coatings in dry cutting operations." Surface and Coatings Technology 146: 480-485.

[3] Sproul, W. D. [1996]. "Physical vapor deposition tool coatings." Surface and Coatings Technology 81(1): 1-7.

[4] Cselle, T. and A. Barimani [1995]. "Today's applications and future developments of coatings for drills and rotating cutting tools." Surface and Coatings Technology 76: 712-718.

[5] Constantin, R. and B. Miremad [1999]. "Performance of hard coatings, made by balanced and unbalanced magnetron sputtering, for decorative applications." Surface and Coatings Technology 120: 728-733.

[6] Navinšek, B., et al. [1997]. "Industrial applications of CrN (PVD) coatings, deposited at high and low temperatures." Surface and Coatings Technology 97: 182-191. 
Moataz H. Ata et al., Effect of nitrogen gas ratio on the properties of TI-ZR-N coatings deposited ...

[7] Probst, J., et al. [2001]. "Binary nitride and oxynitride PVD coatings on titanium for biomedical applications." Surface and Coatings Technology 148: 226-233.

[8] Milošv, I., et al. [1995]. "Electrochemical and thermal oxidation of TiN coatings studied by XPS." Surface and interface analysis 23: 529-539.

[9] Milošev, I., et al. [1997]. "Comparison of $\mathrm{TiN}, \mathrm{ZrN}$ and $\mathrm{CrN}$ hard nitride coatings: Electrochemical and thermal oxidation." Thin solid films 303: 246-254.

[10] Cavaleiro, A., et al. [2006]. The Influence of the Addition of a Third Element on the Structure and Mechanical Properties of Transition-Metal-Based Nanostructured Hard Films: Part I-Nitrides. Nanostructured Coatings, Springer: 261-314.

[11] Luo, Q., et al. [2009]. "Effect of tribofilm formation on the dry sliding friction and wear properties of magnetron sputtered TiAlCrYN coatings." Tribology letters 34: 113-124.

[12] Singh, K., et al. [2005]. "Wear studies of (Ti-Al) N coatings deposited by reactive magnetron sputtering." Wear 258: 1813-1824.

[13] Gilewicz, A., et al. [2016]. "Corrosion resistance of $\mathrm{CrN}$ and $\mathrm{CrCN} / \mathrm{CrN}$ coatings deposited using cathodic arc evaporation in Ringer's and Hank's solutions." Surface and Coatings Technology 299: 7-14.

[14] Scheffel, B., et al. [2016]. "Reactive high-rate deposition of titanium oxide coatings using electron beam evaporation, spotless arc and dual crucible." Surface and Coatings Technology 287: 138-144.

[15] Zhang, S., et al. [2013]. "A superhard CrAlSiN superlattice coating deposited by multi-arc ion plating: I. Microstructure and mechanical properties." Surface and Coatings Technology 214: $160-16$.

[16] Minami, T., et al. [2016]. "Textured surface structures formed using new techniques on transparent conducting Al-doped zinc oxide films prepared by magnetron sputtering." Thin solid films.

[17] Miyagi, T., et al. [2003]. "Pulse mode effects on crystallization temperature of titanium dioxide films in pulse magnetron sputtering." Thin solid films 442: 32-35.

[18] O'brien, J. and P. Kelly. [2001]. "Characterisation studies of the pulsed dual cathode magnetron sputtering process for oxide films." Surface and Coatings Technology 142: 621627.

[19] Knotek, O., et al. [1988]. "The structure and composition of $\mathrm{Ti} \square \mathrm{Zr} \square \mathrm{N}, \mathrm{Ti} \square \mathrm{Al} \square \mathrm{Zr} \square \mathrm{N}$ and Ti $\square \mathrm{Al} \square \mathrm{V} \square$ N coatings." Materials Science and Engineering: A 105: 481-48.

[20] Lin, Y.-W., et al. [2010]. "Effect of nitrogen flow rate on properties of nanostructured TiZrN thin films produced by radio frequency magnetron sputtering." Thin solid films $\mathbf{5 1 8}$ 7308-7311.

[21]ASTM standard E384, ASTM International, [2011], West Con-shohocken, PA 19428-2959.

[22] Uglov, V., et al. [2004]. "Structural characterization and mechanical properties of Ti-Zr-N coatings, deposited by vacuum arc." Surface and Coatings Technology 180: 519-525.

[23] Ramana, J., et al. [2004]. "Structure, composition and microhardness of (Ti, Zr) N and (Ti, $\mathrm{Al}) \mathrm{N}$ coatings prepared by DC magnetron sputtering." Materials Letters 58: 2553-2558.

[24] Uglov, V., et al. [2008]. "Structural and mechanical stability upon annealing of arcdeposited Ti-Zr-N coatings." Surface and Coatings Technology 202: 2394-2398.

[25] Uglov, V., et al. [2006]. "The phase composition and stress development in ternary Ti-Zr$\mathrm{N}$ coatings grown by vacuum arc with combining of plasma flows." Surface and Coatings Technology 200: 6389-6394.

[26] Wang, D.-Y., et al. [2000]. "Synthesis of (Ti, Zr) N hard coatings by unbalanced magnetron sputtering." Surface and Coatings Technology 130(1): 64-68.

[27] Grimberg, I., et al. [1998]. "Multicomponent $\mathrm{Ti}-\mathrm{Zr}-\mathrm{N}$ and $\mathrm{Ti}-\mathrm{Nb}-\mathrm{N}$ coatings deposited by vacuum arc." Surface and Coatings Technology 108: 154-159.

[28] JCPDF No. 381420. 
JES, Assiut University, Faculty of Engineering, Vol. 45, No. 2, March 2017, pp.142-155

[29] Huang, J.-H., et al. [2005]. "Effect of nitrogen flow rate on structure and properties of nanocrystalline TiN thin films produced by unbalanced magnetron sputtering." Surface and Coatings Technology 191: 17-24.

[30] Tsai, D.-C., et al. [2010]. "Effect of nitrogen flow ratios on the structure and mechanical properties of (TiVCrZrY) N coatings prepared by reactive magnetron sputtering." Applied Surface Science 257: 1361-1367.

[31] Tsai, D.-C., et al. [2011]. "Effect of nitrogen flow ratios on the microstructure and properties of (TiVCr) $\mathrm{N}$ coatings by reactive magnetic sputtering." Nuclear Instruments and Methods in Physics Research Section B: Beam Interactions with Materials and Atoms 269: 685-691.

[32] Tsai, D.-C., et al. [2011]. "Structure and mechanical properties of (TiVCr) N coatings prepared by energetic bombardment sputtering with different nitrogen flow ratios." Journal of Alloys and Compounds 509: 3141-3147.

[33] Mason, R. and M. Pichilingi [1994]. "Sputtering in a glow discharge ion source-pressure dependence: theory and experiment." Journal of Physics D: Applied Physics 27: 2363.

[34] Kasemo, B. [2002]. "Biological surface science." Surface science 500(1): 656-677.

[35] Whitehead, S., et al. [1995]. "Comparison of methods for measuring surface roughness of ceramic." Journal of Oral Rehabilitation 22: 421-427.

[36] Lim, Y. J. and Y. Oshida [2001]. "Initial contact angle measurements on variously treated dental/medical titanium materials." Bio-medical materials and engineering 11: 325-341.

[37] Elias, C. N., et al. [2008]. "Relationship between surface properties (roughness, wettability and morphology) of titanium and dental implant removal torque." Journal of the mechanical behavior of biomedical materials 1: 234-242.

[38] Feng, B., et al. [2003]. "Characterization of surface oxide films on titanium and adhesion of osteoblast." Biomaterials 24: 4663-4670.

[39] Blawert, C., et al. [1996]. "Plasma immersion ion implantation of stainless steel: austenitic stainless steel in comparison to austenitic-ferritic stainless steel." Surface and Coatings Technology 85: 15-27.

[40] Zhu, X., et al. [2004]. "Effects of topography and composition of titanium surface oxides on osteoblast responses." Biomaterials 25: 4087-4103.

[41] Scholl, M. [1997]. "Abrasive wear of titanium nitride coatings." Wear 203: 57-64.

[42] Lin, J. F. and J. H. Horng [1994]. "Analysis of the tribological behaviour and wear mechanisms of titanium nitride coating." Wear 171: 59-69.

[43] Lu, Y., et al. [2007]. "Effects of B content and wear parameters on dry sliding wear behaviors of nanocomposite Ti-B-N thin films." Wear 262: 1372-1379.

[44] Chang, C.-L., et al. [2008]. "Influence of bias voltages on the structure and wear properties of TiSiN coating synthesized by cathodic arc plasma evaporation." Thin solid films 516: 5324-5329.

[45] Huang, Z., et al. [1994]. "Friction behaviour of TiN, CrN and (TiAl) N coatings." Wear 173: $13-20$.

[46] Van Stappen, M., et al. [1995]. "State of the art for the industrial use of ceramic PVD coatings." Surface and Coatings Technology 74: 629-633.

[47] Wang, L. L. and X. Y. Nie [2011]. Investigation into tribological properties of TD-treated D2 steel for applications in dry machining of aluminum alloy. Advanced Materials Research, Trans Tech Publ.

[48] Lugscheider, E., et al. [1999]. "PVD hard coated reamers in lubricant-free cutting." Surface and Coatings Technology 112: 146-151.

[49] Komiyama, S., et al. [2015]. "Wear and oxidation behavior of reactive sputtered $\delta$-(Ti, Mo) $\mathrm{N}$ films deposited at different nitrogen gas flow rates." Tribology International 87: 32-39.

[50] Lin, M.-T., et al. [2013]. "Comparison of corrosion behaviors between SS304 and Ti substrate coated with $(\mathrm{Ti}, \mathrm{Zr}) \mathrm{N}$ thin films as Metal bipolar plate for unitized regenerative fuel cell." Thin solid films 544: 162-169.

[51] Lin, Y.-W., et al. [2010]. "Microstructure and corrosion resistance of nanocrystalline TiZrN films on AISI 304 stainless steel substrate." Journal of Vacuum Science \& Technology A 28: 774-778. 
Moataz H. Ata et al., Effect of nitrogen gas ratio on the properties of TI-ZR-N coatings deposited ...

" تأثير نسبة غاز النيتروجين على خصائص طبقات نيتريد التيتانيوم

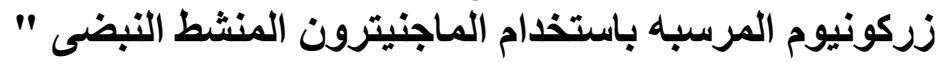

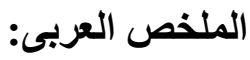

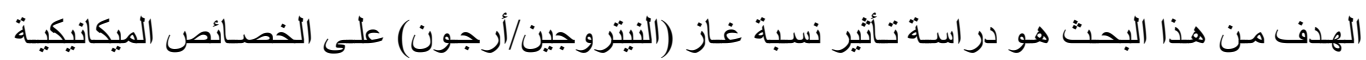

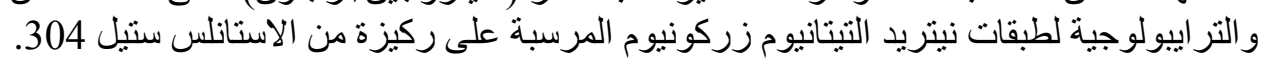

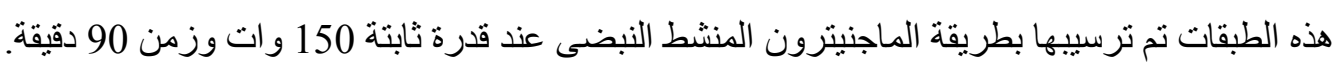

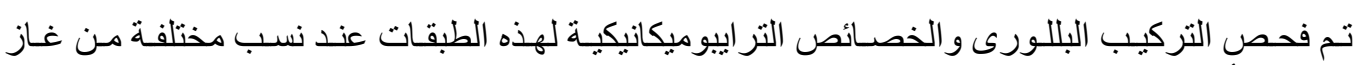
(النيتروجين/أرجون).

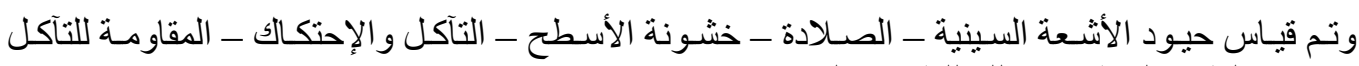
الكيميائى - الطاقة السطحية وذللك للطبقات المرسبة.

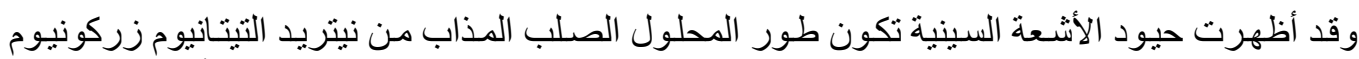

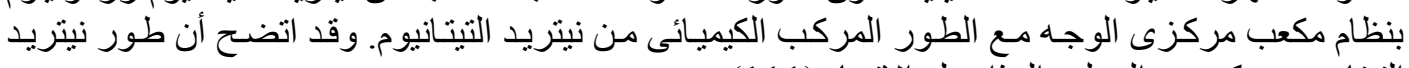
التيتانيوم زركونيوم الصلب المذاب لله الإتجاه (111).

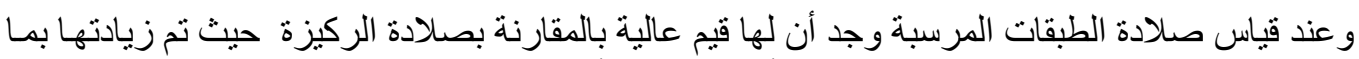

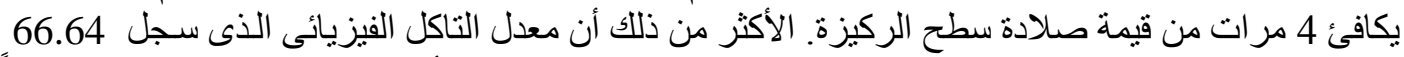

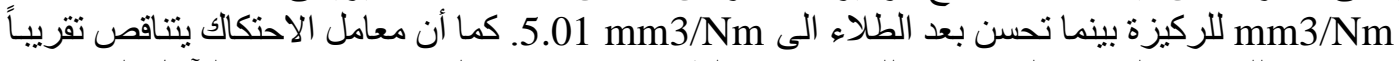

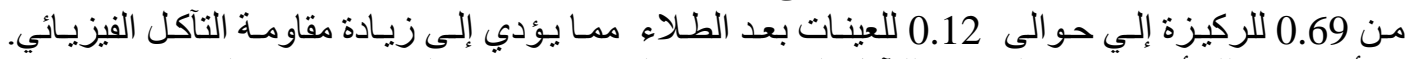
و الأكثر من ذلك أنه تم زيادة المقاومة للتآكل الكيميائي بحو الى للى 1000 مرة بالمقارنة بسطح الركيزة 